\title{
The Effects of Ultra-high Pressure Treatment on the Phenolic Composition of Red Wine
}

\author{
Xiaohuan Chen, Le Li, Yilin You, Bailong Mao, Wenbo Zhao, Jicheng Zhan* \\ College of Food Science and Nutritional Engineering, China Agricultural University, Beijing 100083, China
}

Submitted for publication: February 2012

Accepted for publication: June 2012

Key words: UHP, phenolic acid, flavan-3-ol, proanthocyanidin, red wine

\begin{abstract}
Wine is usually aged in oak barrels. In this study, young red wines were treated with ultra-high pressure (UHP) to stimulate the ageing process. Changes in phenolic acids, flavan-3-ols and proanthocyanidins were determined by reverse-phase high pressure liquid chromatography (RP-HPLC). The concentration of phenolic acids increased, while the levels of flavan-3-ols decreased. The content and structure of proanthocyanidins also changed and the tendency was similar to that of natural ageing.
\end{abstract}

\section{INTRODUCTION}

Ultra-high pressure (UHP), or high hydrostatic pressure (HHP), processing refers to a method in which food is sealed in containers or placed in water or other liquids under pressure $(100 \mathrm{MPa})$ to sterilise and inactivate enzymes or to change the functional properties of a product (Chen, 2005; Zhang et al., 2008b). Under ultra-high pressure, the volume of the product is compressed, which results in the deeper penetration of proteins and other macromolecules into the product, resulting in the destruction of its three-dimensional structure. Thus, UHP not only affects cell morphology, but also changes the hydrogen, ionic and hydrophobic bonds in the three-dimensional structure of biological material. This may, for instance, lead to starch and protein denaturation and enzyme inactivation, all of which may have an effect on the texture of the product. Pressure is instantly and evenly applied to the product, regardless of its size, shape and volume (Bian, 2009). Hite and co-workers have shown that the shelf life of milk, fruits, vegetables and other foods could be prolonged by UHP treatment. Proteins coagulate at $500 \mathrm{MPa}$ and form a gel at $700 \mathrm{MPa}$, which also destroys microorganisms (Bridgman, 1914).

In Japan, UHP technology was applied for the first time in 1986, at the University of Tokyo (Kinugasa et al., 1993). In 1991, the first ultra-pressure products (jam) were introduced into the market, followed by fruit juice and other products. A number of studies on UHP have been performed in Germany and the United States, and many different products have been introduced into the market. In China, UHP technology is focused mainly on food sterilisation and macromolecular degeneration. Litchi juice treated with UHP was shown to have a longer shelf life and to retain its nutritional value (Huang et al., 2007). The treatment of pineapple juice at $400 \mathrm{MPa}$ for $10 \mathrm{~min}$ resulted in improved organoleptic quality (Li et al., 2010a). In sauerkraut, the total number of bacteria was significantly reduced when treated at $600 \mathrm{MPa}$. Lactobacillus spp. were killed and the shelf life of sauerkraut was increased (Li, 2010c). The number of microorganisms and the degree of browning in watermelon juice was reduced after UHP treatment, without there being an effect on the flavour profile (Liu, 2010).

Wine is traditionally aged in oak barrels, which is a lengthy process. This process has been simulated by using high-voltage pulsed electric field ageing, electromagnetic field ageing and microwave ageing (Liu et al., 2006). Some studies have shown that the treatment of wine with UHP results in physical and chemical changes, including changes observed in the ultraviolet and visible spectrum, with an overall improvement in quality $(\mathrm{Li}, 2005)$. The method accelerated wine ageing (Liu et al., 2006). Thus far, little research has been conducted on the UHP treatment of wine.

Phenolic compounds play an important role in the quality of red wine, as they contribute to certain sensory characteristics, particularly colour and astringency. Polyphenols in wine are strong antioxidants and have health benefits. During the ageing of wine, phenols play an important role in wine colour and taste. Thus, specific phenols can be used to follow the ageing process in wine (Minussi et al., 2003; Revilla \& González-SanJosé, 2003; Proestos et al., 2005; Monagas \& Garmen, 2006). The phenols are divided into non-flavonoids and flavonoids. Non-flavonoids are mainly phenolic acids, mostly derivatives of hydroxybenzoic acid and hydroxycinnamic acid. Flavonoids include flavanols, flavonols, anthocyanins and proanthocyanidins. In this paper, the effects of different UHP treatments on the phenolic compounds in wine have been studied.

*Corresponding author: e-mail: jczhan@263.net [Tel.: +86-010-62737553; Fax: +86-10-62737553]

Acknowledgements: The research was funded by the National Key Technology Research and Development Programme, "Study on the key processing technology of high quality wine and industrialization demonstration" (Number 2012BAD31B07) 


\section{MATERIALS AND METHODS}

Equipment and reagents

Liquid chromatography was performed using the WATERS2695XE HHP-700-6 high hydrostatic PATS device and the WATERS Empower Software chromatography data handling system. Methanol and acetonitrile were of HPLC grade (Fisher), and all the remaining reagents were of analytical grade. Catechin [(+)-catechin, CAT], epicatechin [(-)-epicatechin, EC], epigallocatechin [(-)-epigallocatechin, EGC], epicatechin gallate [(-)-epicatechin gallate, ECG] and epigallocatechin gallate [(-)-epigallocatechin gallate, EGCG] were used as flavan-3-ol standards. Gallic acid, protocatechuic acid, p-hydroxy benzoic acid, syringic acid, chlorogenic acid, caffeic acid, coumaric acid, erucic acid, ferulic acid, vanillic acid and gentisic acid were used as phenolic standards. All standards were from Sigma (Sigma Aldrich 3050, Spruce St. St. Louis, Mo 63103) and of 95\% and higher purity.

\section{Detection of phenolic acids}

Phenolic acids were detected by using a 100RP-18e column $(250 \mathrm{~mm} \times 4.0 \mathrm{~mm}$, inner diameter $5 \mu \mathrm{m})$ from Merck LiChrospher (Darmstadt, Germany) and a guard column RP-18 (10 mm × $4 \mathrm{~mm}$ ) from Merck (Darmstadt, Germany). For the first 11 to $15 \mathrm{~min}$ the wave length was set at 320 $\mathrm{nm}$, while it was set at $280 \mathrm{~nm}$ for the rest of the run. The column temperature was set at $30^{\circ} \mathrm{C}$ and $10 \mu \mathrm{L}$ was injected. External standards were used to detect the peak area. Mobile phase A was methanol, acetic acid and water (10:2:88), and mobile phase B was methanol, acetic acid and water (90:2:8). The flow rate was $1 \mathrm{~mL} / \mathrm{min}$. The gradient elution was 0 to 25 min with phase B from $0 \%$ to $15 \% ; 25$ to 45 min with phase B $15 \%$ to $50 \%$; and 45 to 53 min with phase B $50 \%$ to $0 \%$. Samples were filtered through a $0.45 \mu \mathrm{m}$ Millipore membrane before injection.

\section{Detection of flavan-3-ols}

Detection was with a 100RP-18e column $(250 \mathrm{~mm} \times$ $4.0 \mathrm{~mm}$, inner diameter $5 \mu \mathrm{m}$ ) from Merck LiChrospher (Darmstadt, Germany) and a guard column RP-18 (10 mm $\times 4 \mathrm{~mm}$ ) from Merck. The wavelength used was $280 \mathrm{~nm}$, the column temperature $30^{\circ} \mathrm{C}$, and the injection volume was $10 \mu \mathrm{L}$. External standards were used to detect the peak area. Mobile phase A was water and mobile phase B was $10 \%$ glacial acetic acid (90/10). The flow rate was $1 \mathrm{~mL} / \mathrm{min}$. The gradient elution was 0 to $20 \mathrm{~min}$ with B $7.5 \%$ to $65 \% ; 20$ to 30 min with B $65 \%$ to $80 \% ; 30$ to 48 min with B $80 \%$ to $90 \%$; 48 to 55 min with B $90 \%$; and 55 to 63 min with B 7.5\%. Samples were filtered through a $0.45 \mu \mathrm{m}$ Millipore membrane before injection.

\section{Detection of proanthocyanidins}

The method of Pekić et al. (1998) was used for the detection of proanthocyanidins. Solution A was $30 \%(\mathrm{v} / \mathrm{v})$ $\mathrm{H}_{2} \mathrm{SO}_{4} /$ methanol and solution $\mathrm{B}$ was $1 \%$ (w/v) vanilla aldehyde/methanol. The solutions were mixed rapidly and used at a ratio of 1:1. A $0.2 \mathrm{~mL}$ sample was added to $6.0 \mathrm{~mL}$ vanillin and the absorbance was measured at $510 \mathrm{~nm}$ after 5 min. A standard curve was prepared with catechin, using the same protocol.
Separation and purification of proanthocyanidins

Wine $(10 \mathrm{~mL})$ was injected into the TSK HW-50 (F) column $(18 \mathrm{~mm} \times 250 \mathrm{~mm})$ and eluted with $90 \mathrm{~mL}$ ethanol/water/TFA $(55 / 45 / 0.05)$ and $50 \mathrm{~mL}$ acetone/water $(60 / 40$, containing $1 \mathrm{~g} / \mathrm{L}$ of vitamin $\mathrm{C}, \mathrm{Vc}$ ). The flow rate was $1.5 \mathrm{~mL} / \mathrm{min}$. The samples were freeze-dried and stored at $20 \mathrm{C}$.

\section{Degradation of proanthocyanidins}

The freeze-dried samples were dissolved in $2.5 \mathrm{~mL}$ methanol (HPLC). One $1 \mathrm{~mL}$ was added to $0.5 \mathrm{~mL} 0.2 \mathrm{~N} \mathrm{HCl} / \mathrm{MeOH}$ (containing $20 \mathrm{~g} / \mathrm{L}$ ascorbic acid) and $0.5 \mathrm{~mL} 100 \mathrm{~g} / \mathrm{L}$ phloroglucinol. This was heated to $50^{\circ} \mathrm{C}$ for $20 \mathrm{~min}$ and then added to $40 \mathrm{mM}$ b-sodium to terminate the reaction. Samples were stored at $-20^{\circ} \mathrm{C}$.

\section{Chromatography conditions to detect proanthocyanidins degradation}

A 100RP-18e column $(250 \mathrm{~mm} \times 4.0 \mathrm{~mm}$, inner diameter $5 \mu \mathrm{m})$ from Merck LiChrospher (Darmstadt, Germany) and a guard column RP-18 $(10 \mathrm{~mm} \times 4 \mathrm{~mm})$ from Merck (Darmstadt, Germany) were used. Detection was at $280 \mathrm{~nm}$, the column temperature was $30^{\circ} \mathrm{C}$ and the flow rate $1.5 \mathrm{~mL} /$ min. The injection volume was $10 \mu \mathrm{L}$. A standard curve was prepared with catechin, prepared using the same protocol. Mobile phase A was $1 \%(\mathrm{v} / \mathrm{v})$ acetic acid and mobile phase B was $80 \%$ acetonitrile (1\%, v/v, acetic acid). The following gradient was applied: elution 0 to 8 min with $3.8 \% \mathrm{~B} ; 8$ to 28 min with 3.8 to $22.5 \% \mathrm{~B} ; 28$ to 32 min with 22.5 to $50 \%$ B; 32 to 50 min with 50 to $100 \%$ B; 50 to 52 min with $100 \%$ B; and 52 to $60 \mathrm{~min}$ with $3.8 \% \mathrm{~B}$. Samples were filtered through a $0.45 \mu \mathrm{m}$ Millipore membrane before injection.

\section{Standard curves of $\mathbf{1 1}$ phenolic acids}

Standard samples of 10 different phenolic acids were prepared, as shown if Fig. 1. The peak order is gallic acid at $4.904 \mathrm{~min}$; protocatechuic acid at $9.332 \mathrm{~min}$; P-hydroxy benzoic acid at $15.788 \mathrm{~min}$; chlorogenic acid at 20.102 min; vanillic acid at $21.508 \mathrm{~min}$; caffeic acid at $22.656 \mathrm{~min}$; syringic acid at $26.358 \mathrm{~min}$; p-coumaric acid at $33.232 \mathrm{~min}$; ferulic acid at $36.714 \mathrm{~min}$; and erucic acid at $37.792 \mathrm{~min}$. Fig. 2 shows gentisate at $13.743 \mathrm{~min}$.

\section{Standard working curves of five flavan-3-ols}

The samples are presented in Fig. 3. The peak order is as follows: (+)-catechin at $22.866 \mathrm{~min}$; (-)-epigallocatechin at $23.823 \mathrm{~min}$; (-)-epigallocatechin gallate at $31.611 \mathrm{~min}$; (-)-epicatechin at $35.925 \mathrm{~min}$; (-)-epicatechin gallate at $50.913 \mathrm{~min}$.

\section{Standard curve of proanthocyanidin degradation}

The proanthocyanidin standard curve is shown in Fig. 4. The peak order is as follows: CAT, $16.298 \mathrm{~min}$; EC 21.750 min; ECG $28.152 \mathrm{~min}$. Other degradation products were qualitatively analysed as described by Pengfei (2005).

\section{Preparation of wine samples}

The samples were wine from Xinjiang's 2009 Cabernet Sauvignon. The first group of wine was treated at $100 \mathrm{MPa}$, $200 \mathrm{MPa}, 300 \mathrm{MPa}, 400 \mathrm{MPa}, 500 \mathrm{MPa}$ and $600 \mathrm{MPa}$ for $30 \mathrm{~min}$. The second group of wine was treated for $5 \mathrm{~min}, 10$ 


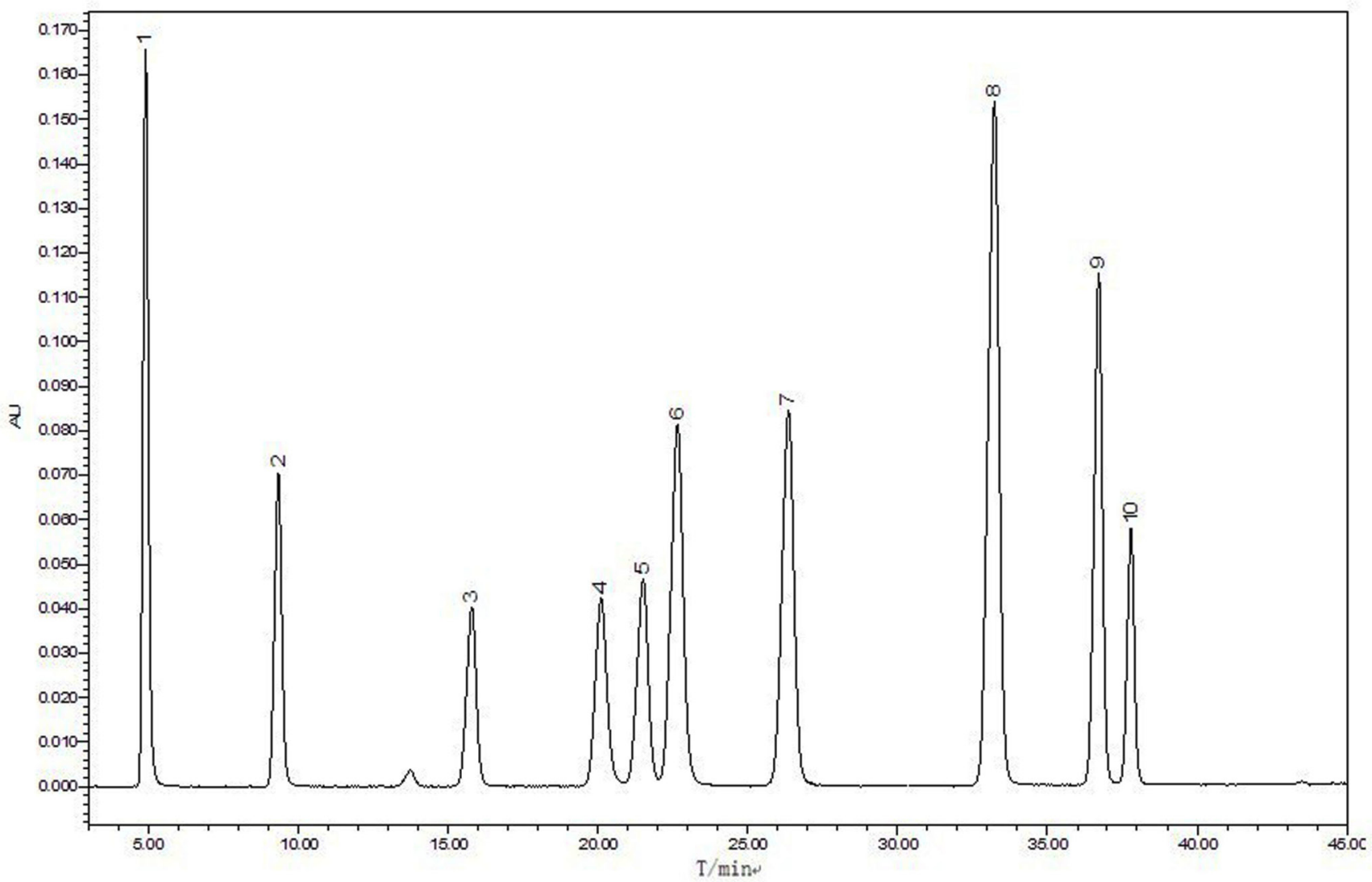

FIGURE 1

Chromatography of 10 phenolic acid standards

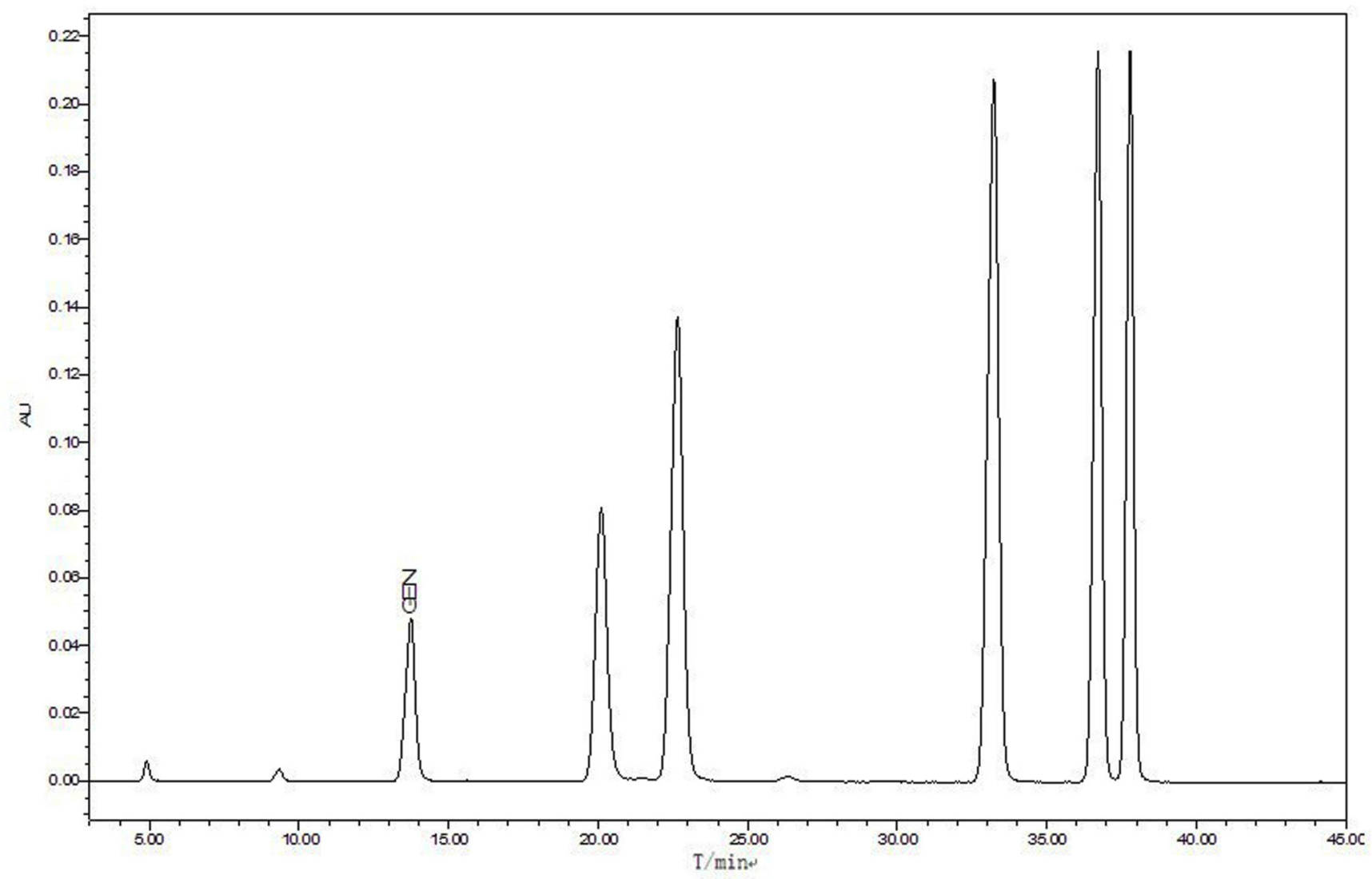

FIGURE 2

Chromatography of gentisic acid standards 


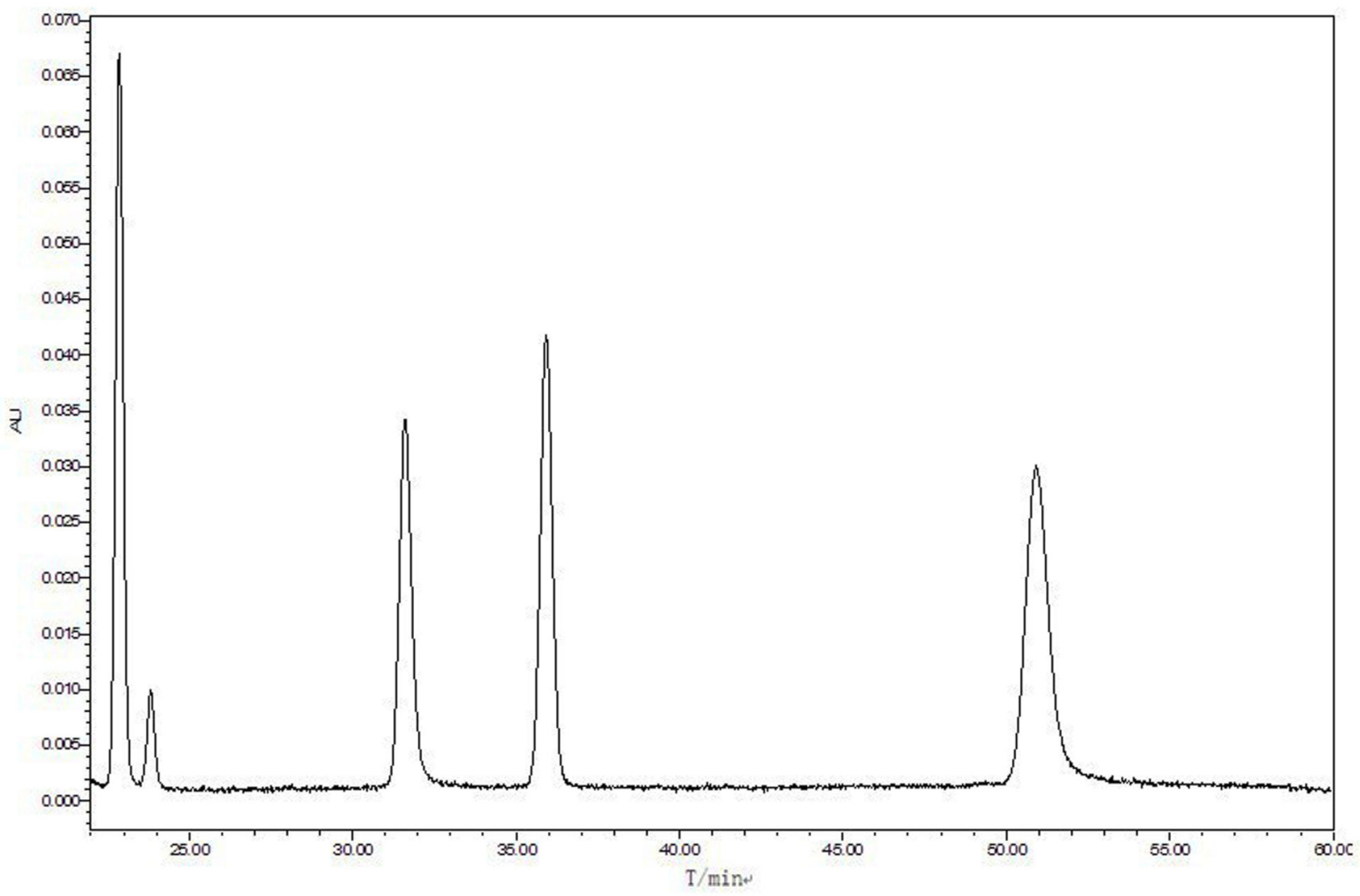

FIGURE 3

Chromatography of five flavan-3-ol standards

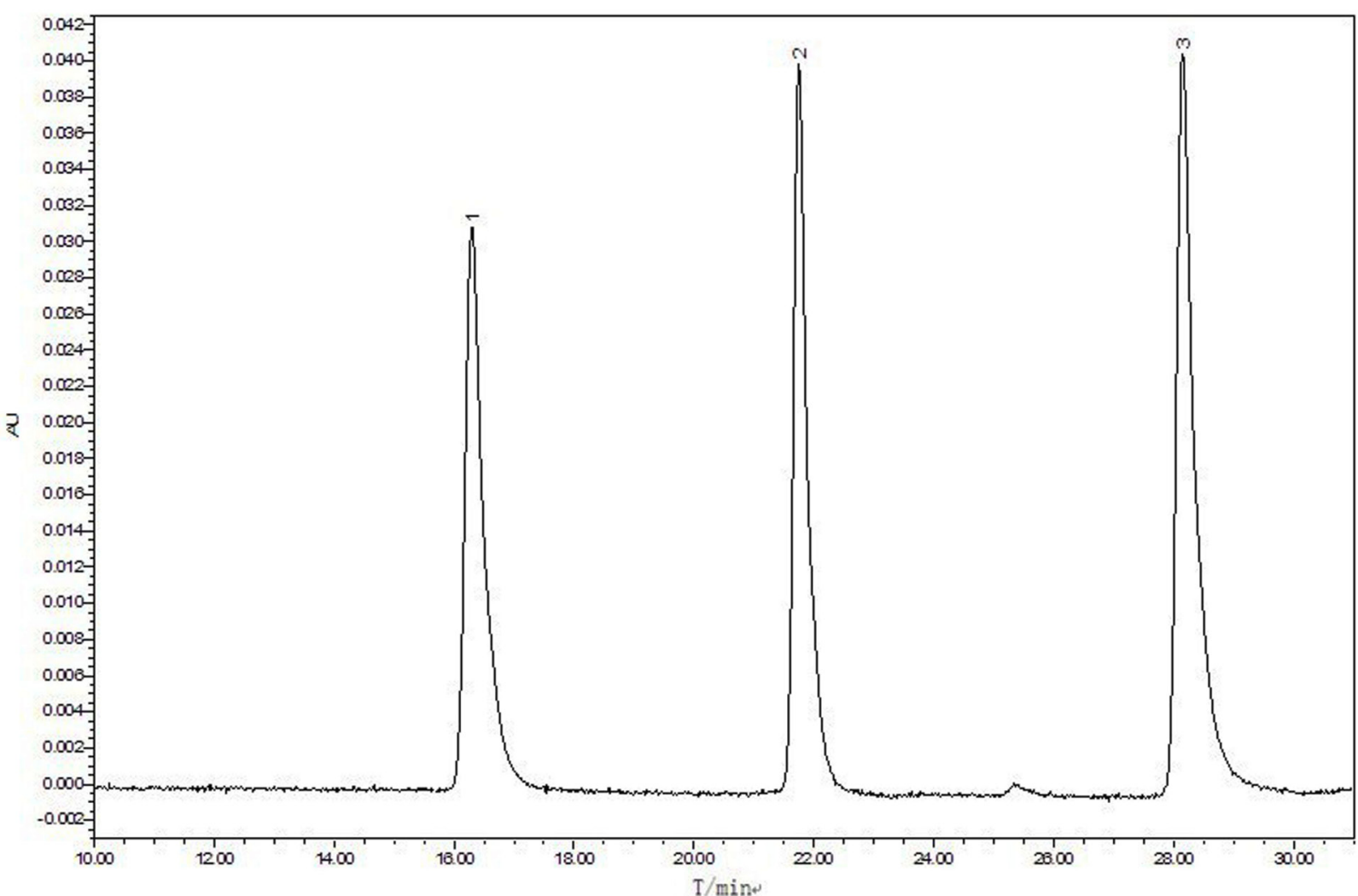

FIGURE 4

Chromatogram of three flavanol-ol standards 
min, $20 \mathrm{~min}, 30 \mathrm{~min}, 45 \mathrm{~min}$ and $60 \mathrm{~min}$ at $500 \mathrm{MPa}$. All samples were filtered through a $0.45 \mu \mathrm{m}$ organic Millipore filter (Merck Millipore, 290 Concord Road, Billerica, MA, USA). Tests were repeated in triplicate and the results were analysed by Sigmaplot 11.0 and SPSS 17.0.

\section{RESULTS AND DISCUSSION}

\section{Effects of UHP treatment on phenolic acids in young red wine}

The content of total phenolic acids in the wine after UHP treatment is shown in Fig. 5. At a pressure of $100 \mathrm{MPa}$, the total content of phenolic acids increased rapidly and reached its highest point at a pressure of $200 \mathrm{MPa}$. After this point, the total content of phenolic acids declined as the pressure increased to $400 \mathrm{MPa}$. No drastic changes were recorded at pressures higher that $400 \mathrm{MPa}$. Treatment at $500 \mathrm{MPa}$ for 5 min resulted in an increase in the total phenolic content, followed by small fluctuations as time continued. The phenolic content stabilised after $30 \mathrm{~min}$.

The 11 phenolic acids changed with the range of pressures and treatment times ( $\mathrm{P}<0.05$; Fig. 6). Besides P-coumaric acid, ferulic acid changed to a lesser extent, and the ranges of the other nine phenolic acids were similar to an extent, but the trends varied greatly. Gallic acid content reached its highest level at $100 \mathrm{MPa}$, followed by mild fluctuations. The remaining phenolic acids also reached a maximum at 100 MPa or $200 \mathrm{MPa}$, followed by slight fluctuations.

With the treatment time prolonged, the content of the other 10 phenolic acids, in addition to gentisate, changed significantly $(\mathrm{P}<0.05)$. Gallic acid and syringic acid, which were present at a higher concentration, changed the most. Chlorogenic acid, caffeic acid and sinapic acid also showed a more significant change, while P-coumaric acid and ferulic acid did not change that much. Among the 11 phenolic acids, the gallic acid content was the highest, as observed in previous studies (Minussi et al., 2003). At processing for 5 to $10 \mathrm{~min}$, the concentration of gallic acid and syringic acid increased substantially, and as the time increased to 30 min, they gradually dropped to levels close to those recorded before processing. The levels of chlorogenic acid increased rapidly after $5 \mathrm{~min}$, followed by a stable increase.

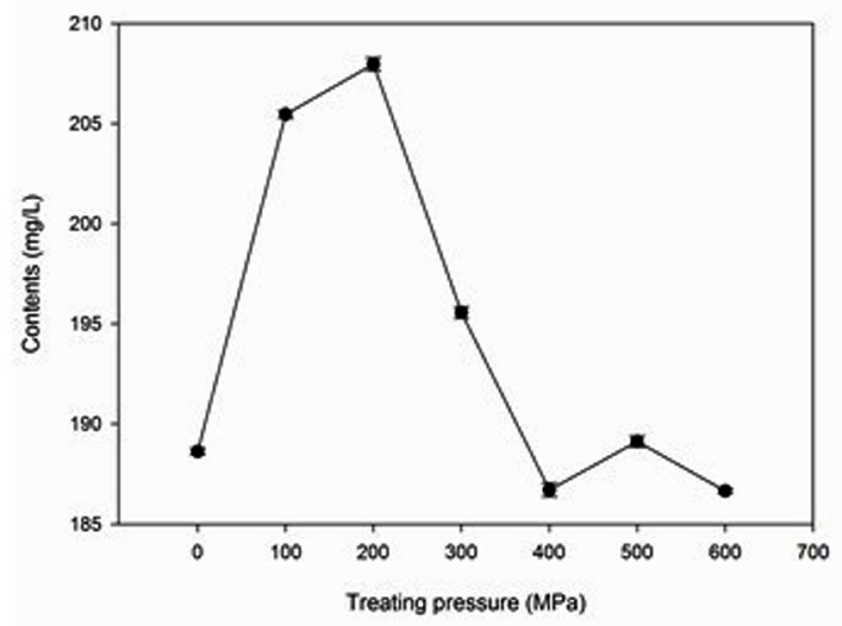

Many factors affect the phenolic content of wine, including grape variety and maturity (Recamales et al., 2006). The fermentation process also affects the phenolic content, such as length of soaking time and fermentation temperature. Studies have shown that, if wine ferments at low temperatures, the levels of syringic acid, coumaric acid, sinapic acid and gentisic acid increase (Ramos et al., 1999). During the wine fermentation and ageing process, phenolic polymerisation and oxidation reactions occur and the complexity changes. In wine, phenolic acids can combine with anthocyanins and tartaric acid, such as p-coumaric acid and caffeic acid. The combination of the latter may lead to the formation of tartar coumaric acid and tartaric caffeic acid. The hydrolysis of these compounds produces free phenolic acids. Gallic tannins are hydrolysed to gallic acid, especially during the ageing process. Microorganisms participate in the metabolism of hydroxyl cinnamic acid to generate volatile phenols. After malolactic fermentation, the content of caffeic acid, tartaric acid esters and P-coumaric acid decreases, whilst the corresponding free acid content increases. During oak ageing, tannins are hydrolysed to generate ellagic acid, resulting in an increase in ellagic acid levels. At the same time, gentisic acid and caffeic acid levels also increase (Ramos et al., 1999; Lee et al.. 2002). After UHP treatment, the complexity of the phenolic acids changed, but with an overall upward trend, possibly because of the pressure that promoted the decomposition of certain compounds, which led to the content of the corresponding phenolic acids increasing. However, when the pressure was above $200 \mathrm{MPa}$, the phenolic acid content declined, probably because oxidation stepped in at the higher pressure.

\section{The effect of UHP treatment on flavan-3-ols in young red wine}

The change in the total content of flavan-3-ols in the wine is shown in Fig. 7. As the pressure increased, the content of the flavan-3-ol decreased. The flavan-3-ol levels increased slightly at $100 \mathrm{MPa}$, and then decreased with the increase in handling pressure, especially at $500 \mathrm{MPa}$ and $600 \mathrm{MPa}$. The content of flavan-3-ol dropped slightly at $5 \mathrm{~min}$, and then increased to a maximum at $10 \mathrm{~min}$. The lowest point was

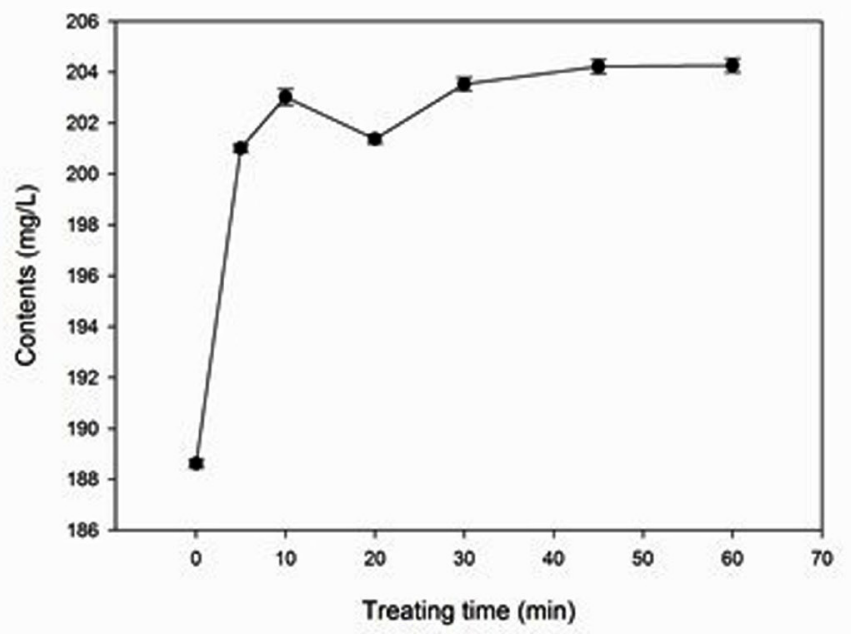

FIGURE 5

Changes in total phenolic acids in red wine treated by UHP 
reached at $45 \mathrm{~min}$.

Four of the flavan-3-ols showed significant differences $(\mathrm{P}<0.05)$ under different treatment conditions (Fig. 8). With the pressure increasing, the CAT content fluctuated and declined at $100 \mathrm{MPa}$ and $200 \mathrm{MPa}$. At $400 \mathrm{MPa}$, the content of EGC, EGCG and EC decreased as the pressure increased. At $500 \mathrm{MPa}$, with prolonged treatment, the four levels of the flavan-3-ols decreased, with the content of CAT at its lowest at $45 \mathrm{~min}$. The levels recovered at $60 \mathrm{~min}$; EGC and EC showed a tendency to first increase and then decrease. The content of EGCG decreased at 10 min and remained at his level

CAT and EC are the main flavan-3-ol compounds in wine. ECG cannot be detected in wine samples. Wen et al. (2006) studied the impact of oak on the flavan-3-ols and found that ECG can only be detected later in ageing. Flavan-3-ols have a taste of bitterness and astringent. During storage, flavan-3-ols can participate in, or mediate, procyanidin condensation, and combine with anthocyanins to generate polymeric pigments, thus changing the colour of the wine. During ageing, with the help of the acetaldehyde, flavan-3-ols can undergo intense chemical reactions, such as condensation between anthocyanins, flavanols, anthocyanins and flavanols, or they can condensate with anthocyanins without acetaldehyde. Micro-oxygen could cause a slight oxidation of the flavan-3ols. Flavan-3-ols may also be involved in the decomposition and polymerisation of proanthocyanidins and promote the polymerisation of proanthocyanidins (Vidal et al., 2002). At the same time, proanthocyanidins may release free flavan3-ols. UHP treatment may contribute to the polymerisation reactions, with a decrease in flavan-3-ol content.

\section{Effect of UHP treatment on the content of proanthocya- nidins}

The changes in the content of proanthocyanidins after UHP treatment are shown in Fig. 9. As the pressure increased, the proanthocyanidin levels increased. At $100 \mathrm{MPa}$, the levels went down slightly, and then increased substantially at $200 \mathrm{MPa}$. At $300 \mathrm{MPa}$ and $400 \mathrm{MPa}$ a slightly decline was observed. The proanthocyanidin levels showed an upward
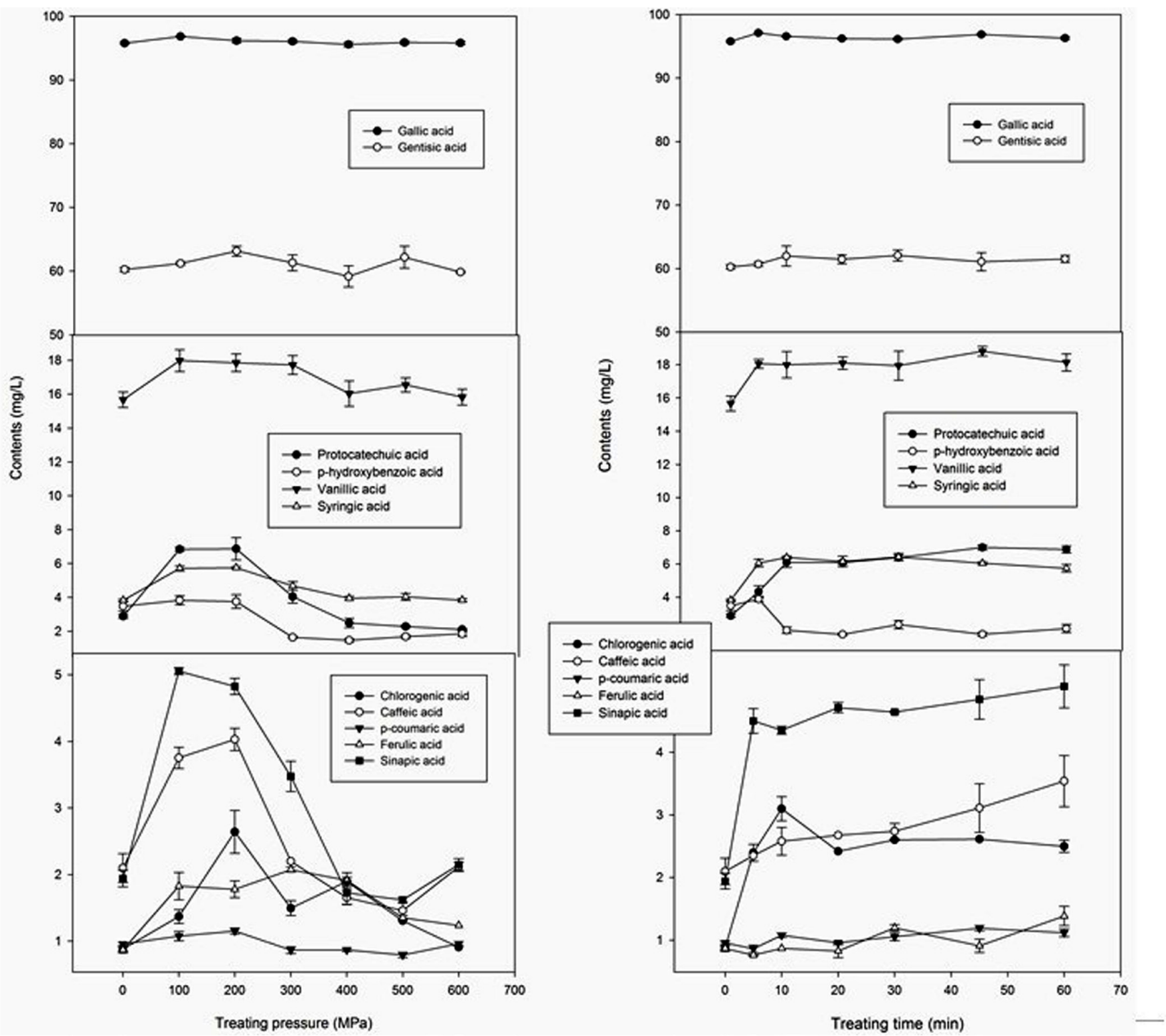

FIGURE 6

Changes in 11 phenolic acids in red wine treated by UHP 
tide as treatment continued, but lowered slightly at $10 \mathrm{~min}$. Thereafter the content gradually increased, reached the maximum at $45 \mathrm{~min}$, and decreased at $60 \mathrm{~min}$.

The basic structural unit of proanthocyanidins is flavan3-ol, which plays an important role in the sensory quality

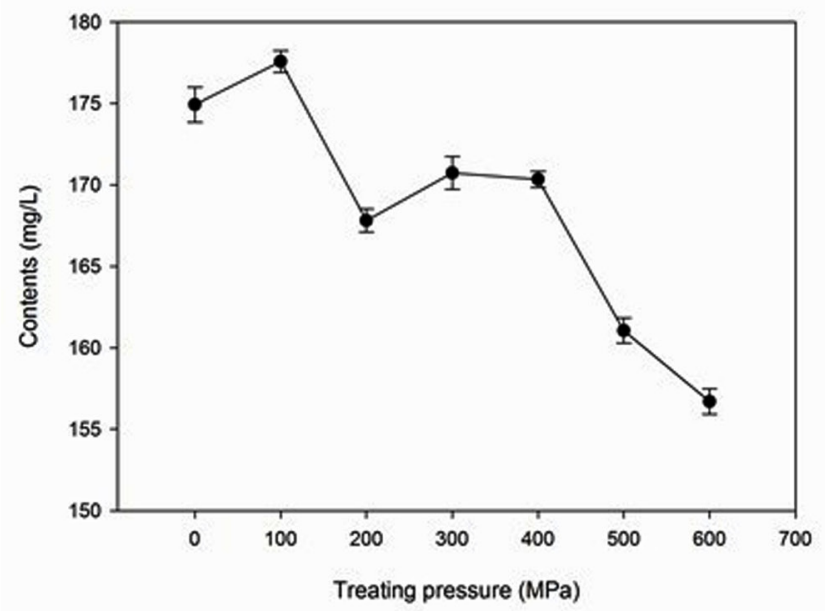

of wine. Proanthocyanidins undergo complex reactions during wine storage and ageing. Studies have shown that the content of anthocyanins first increases rapidly, and then declines slowly during bottle storage (Su, 2008). This may be because flavan-3-ol condenses during ageing, thus

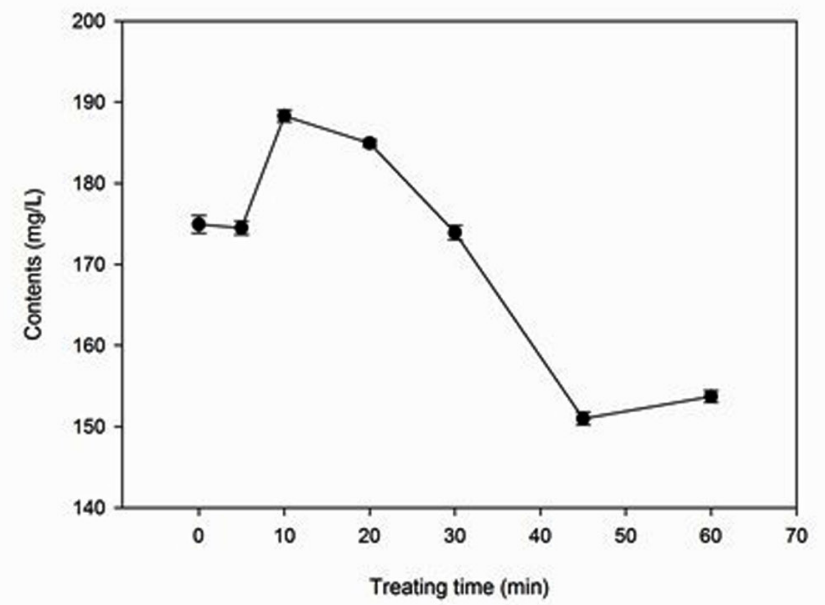

FIGURE 7

Changes in total flavan-3-ols in red wine treated by UHP
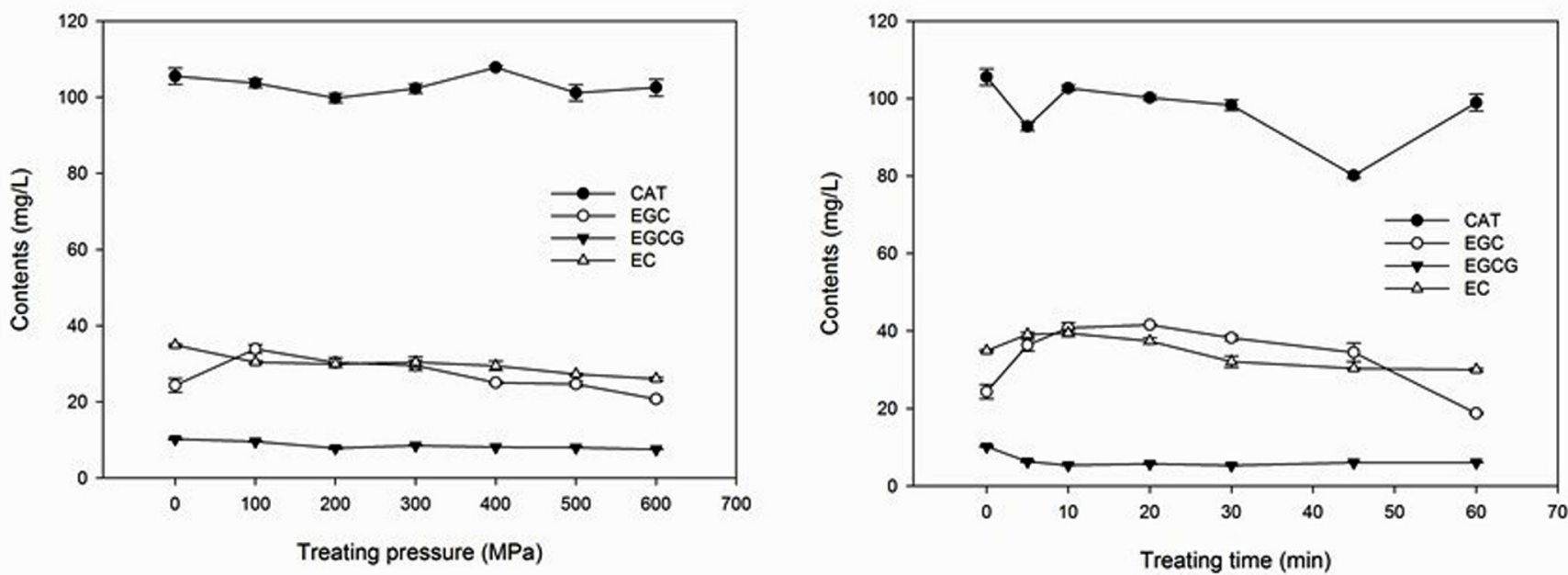

FIGURE 8

Changes in four flavan-3-ols in red wine treated by UHP
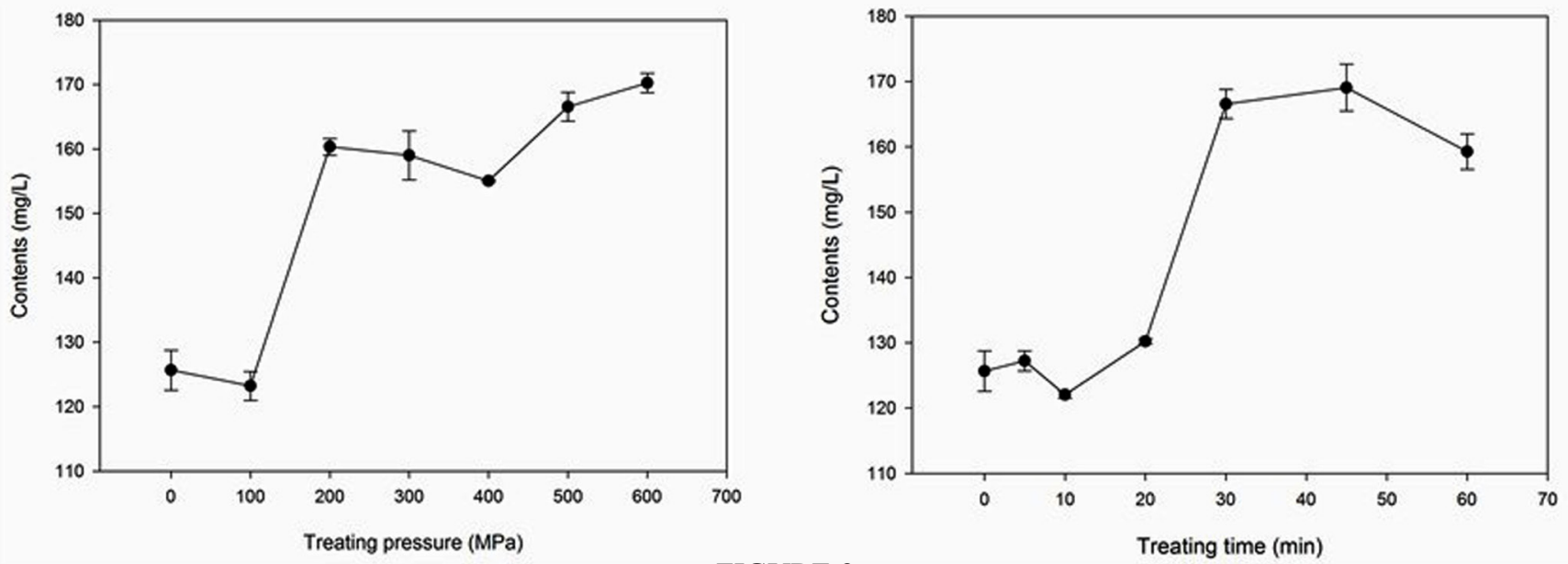

FIGURE 9

Changes in proanthocyanidins in red wine treated by UHP 
increasing the concentration of proanthocyanidins. Another study found that proanthocyanidins decrease after oak ageing, especially in European oak. Proanthocyanidins can condensate to generate high-molecular compounds such as tannin analogues (Guadalupe \& Ayestarán, 2008) with polysaccharides, proteins, etc. This will lead to a reduced content of proanthocyanidins.

With increasing pressure, the content of proanthocyanidins increased, probably because the pressure narrowed the intermolecular distance while providing
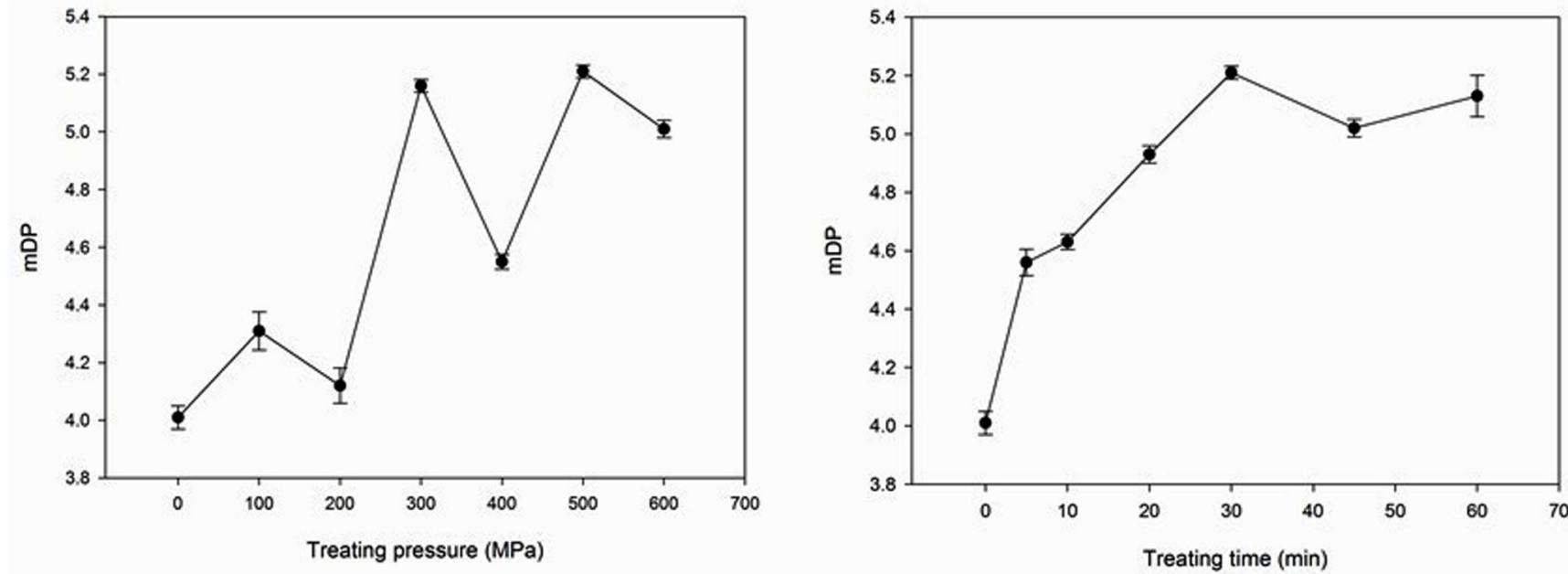

FIGURE 10

Changes in ADP of proanthocyanidins in red wine treated by UHP
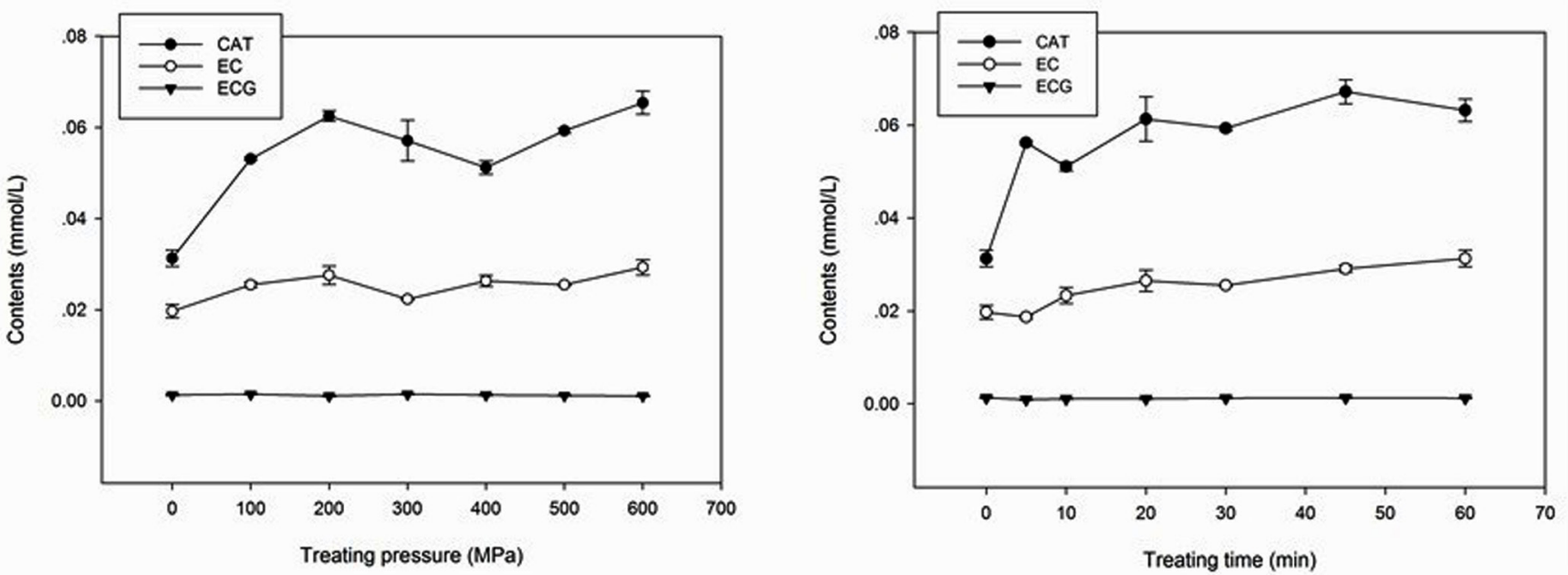

FIGURE 11

Changes in starting units of proanthocyanidins in red wine treated by UHP
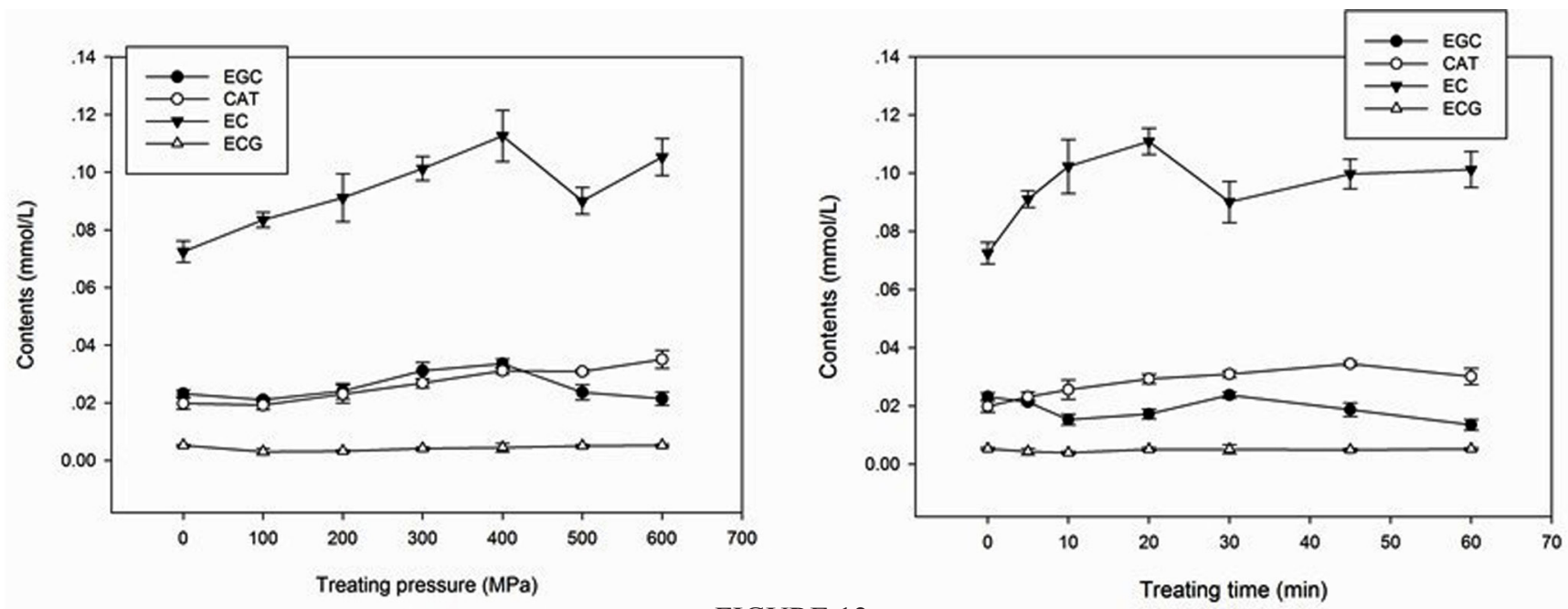

FIGURE 12

Changes in extension units of proanthocyanidins in red wine treated by UHP 
energy, which is beneficial to the structural unit of the condensation reaction. On the other hand, the high-pressure conditions can also affect the condensation reaction between proanthocyanidins and other macromolecules. Thus, under certain stress conditions, the content of proanthocyanidins decreased slightly. On the whole, the content dropped. As treatment was prolonged, the proanthocyanin levels also showed a clear upward trend, indicating that continuing pressure is conducive to the formation of proanthocyanins. At 10 min the content tailed off slightly, probably because different processing times influence the condensation reactions that proanthocyanidins are involved in.

\section{Effect of UHP treatment on the average degree of polymerisation of proanthocyanidins}

Treatment under different conditions and changes in the average degree of polymerisation of proanthocyanidins is are shown in Fig. 10. With an increase in pressure, the average degree of polymerisation showed an upward tendency, similar to a wave effect. At $100 \mathrm{M} \mathrm{Pa}$, the degree of polymerisation increased, then decreased slightly. A significant increase was observed at $300 \mathrm{MPa}$, after which it fluctuated. The average degree of polymerisation of proanthocyanidins showed a clear upward trend as treatment continued, reaching a peak at $30 \mathrm{~min}$. This was followed by a slight decrease.

During the ageing process, proanthocyanidins react with anthocyanins and precipitate, while the flavan-3-ol can combine with oligomer proanthocyanidins to generate polyproanthocyanidins in the presence of acetaldehyde (Vidal et al., 2004). On the other hand, proanthocyanidins may be subjected to reaction with nucleophile agents (e.g. EC) and generate oligomeric proanthocyanidins. The two reactions happen at the same time; the dynamic equilibrium process leads to the volatility of the average degree of polymerisation of proanthocyanidins.

With the increase of pressure, the average degree of polymerisation of the proanthocyanidins fluctuated and changed, but showed an overall upward trend. This may be because high pressure can promote some related reactions, similar to what happens in the ageing process. As treatment increased, polymerisation increased significantly, illustrating that a sustained increase in pressure can promote the polymerisation reaction to generate poly- proanthocyanidins.

\section{Effect of UHP treatment on proanthocyanidins}

Anthocyanins also undergo a change after UHP treatment (Fig. 11). With an increase in pressure, the content of CAT and EC changed, while ECG itself had a lower level at the start. At $100 \mathrm{MPa}$ and $200 \mathrm{MPa}$, the content of CAT and EC increased and then decreased when the pressure increased to above $400 \mathrm{MPa}$. The content of CAT first increased, declined slightly at $10 \mathrm{~min}$, and then increased. The content of EC decreased slightly at first, but then gradually increased as treatment prolonged. The content of ECG did not change significantly.

During ageing, the composition of proanthocyanidins also changed dramatically. Proanthocyanidins and macromolecules can polymerise, resulting in a decrease in initial concentrations. Flavan-3-ol monomers condensate to generate the proanthocyanidins with acetaldehyde. The processes reach a dynamic equilibrium during ageing.

After pressure treatment, the content of CAT and EC increased. With prolonged pressure a new dynamic equilibrium formed. High pressure may be more conducive to promote reactions and can increase the condensation of flavan-3-ol and the cleavage of proanthocyanidins, leading to an increase in the CAT and EC content. The increase in EC concentration was more obvious when the processing time was longer than $30 \mathrm{~min}$.

\section{Effect of UHP treatment on the extension units of proanthocyanidins}

The changes in the extension units of proanthocyanidins after pressure treatment are shown in Fig. 12. With the pressure increasing, the content of EC and CAT showed an upward trend. While the content of EGC first went up and then decreased, the change was less obvious. The highest level of EC was recorded at $400 \mathrm{MPa}$, but it decreased at $500 \mathrm{MPa}$. As time passed, the content of EC showed an "up-down-up" trend. This was more obvious when the processing time was less than $20 \mathrm{~min}$. EC is the main "extension unit", and has the highest concentration, followed by CAT and EGC. Similar to the starting unit, the content of the "extension unit" also shows changes in volatility. After bottle storage, the content of the EC and CAT "extension units" in proanthocyanidins increased ( $\mathrm{Su}, 2009)$.

After the UHP treatment, the content of EC and CAT increased, possibly because the high pressure promoted EC and CAT to participate in the polymerisation of proanthocyanidins, which generated an "extension unit". The content of EC increased, although it fluctuated. The content of EGC first increased and then decreased, but ECG showed no significant changes due to its low level. With an increase in time, the content of EC and CAT increased, illustrating that long periods at high pressure are conducive to promote EC and CA to participate in the formation of proanthocyanidins as structural units.

\section{CONCLUSION}

After UHP treatment, the polyphenol levels in wine changed dramatically. The content changes of 11 phenolic acids were totally different, but showed an overall upward trend, possibly because the pressure promoted the decomposition of some compounds. This led to an increase in the content of the corresponding phenolic acids. The content of flavan-3-ols declined, while the content of proanthocyanidins increased. The concentration of the "initial unit" and "extension unit" also increased, probably because high-pressure conditions promoted the formation of proanthocyanidins, which use flavan-3-ols as structural units. At the same time, UHP influenced the polymerisation and cleavage reactions that proanthocyanidins are involved in. Thus, the average degree of polymerisation of the proanthocyanidins and the content of the "composition unit" showed similar fluctuations, just like the natural changes during the ageing process. The effect of UHP on wine compounds is rather complex and more indepth research will have to be done to attain a theoretical basis for changes taking place during artificial ageing. 


\section{LITERATURE CITED}

Bai, Y.H., Gong, G.Y. \& Deli, G.E., 2004. The impacts of high pressure treatment on the sensory characteristics and microstructure of cattle, sheep and muscle. Food Sci. Technol. 25, 67-69.

Balogh, T., Smout, C., Nguyen, B. L., Van, L. A., Hendrickx, M. 2004. Thermal and high-pressure inactivation kinetics of carrot pectin methylesterase: From model system to real foods. Innov. Food Sci. Emerg. Technol. 5, 429-436.

Bian, L., 2009. The impacts of pressure treatment on blackberry aroma, texture characteristics and peroxidase. Thesis, Jiangsu University. China.

Boulton, R. B., 2001. The copigmentation of anthocyanins and its role in the color of red wine: A critical review. Am. J. Enol. Vitic. 52, 67-87.

Bridgman, P. W., 1914. The technique of high pressure experimenting. Proc. Am. Academ. Arts Sci. 49, 627-643.

Chen, F.S., 2005. Ultra-high pressure food processing technology. Chemical Industry Press, Beijing.

Cheynier, V., Remy, S. \& Fulcrand, H., 2000. Mechanisms of anthocyanin and tannin changes during winemaking and aging. Proceedings of the ASEV 50th anniversary annual meeting, Seattle, Washington, June 19-23, 337-344.

Chong, P.L.G.., Cossins, A.R. \& Weber, G., 1983. A differential polarized fluorometric study of the effects of high hydrostatic pressure upon the fluidity of cellular membranes. Biochem. 22, 409-415.

Cong, W., Zhang C.Y. \& Zhang, W.Y., 2007. The changes of pineapple aroma components before and after the pressure treatment. Food Sci. Technol. Int. 3, 67-71.

Corrales, M., Butz, P. \& Tauscher, B. 2008. Anthocyanin condensation reactions under high hydrostatic pressure. Food Chem. 10, 627-635.

Fan, S.H., 2007.Studies about the dry red wine aroma components under high pulsed electric fields, Thesis, Jilin Agricultural University, China.

Fulcrand, H., Doco, T., Es-Safi, N., Cheynier, V., Moutounet, M.,1996. Study of the acetaldehyde induced polymerization of flavan-3-ols by liquid chromatography ion spray mass spectrometry. J. Chromatogr. 752, 85-91.

Gambelli, L. \& Santaroni, G.P., 2004. Polyphenols content in some Italian red wines of different geographical origins. J. Food Comp. Anal. 17, 613 618.

Garcia-Palazon, A., Suthanthangjai, W., Kajda, P., Zabetakis, I., 2004 The effects of high hydrostatic pressure on B-glucosidase, peroxidase and polyphenoloxidase in red raspberry (Rubus idaeus) and strawberry (Fragaria $\times$ ananassa). Food Chem. 88, 7-10.

García-Puente, R.E., Alcalde-Eon, C., Santos-Buelga, C., Rivas-Gonzalo, J.C. \& Escribano-Bailón, M. T., 2006. Behaviour and characterization of the color during red wine making and maturation. Anal. Chim. Acta 563, 215-222.

Guadalupe, Z. \& Ayestarán, B., 2008. Changes in the color components and phenolic content of red wines from Vitis vinifera L. Cv. "Tempranillo" during vinification and aging. Eur. Food Res. Technol. 228, 29-38.

Gutiérrez, I.H., Lorenzo, ES-P. \& Espinosa, A.V., 2005. Phenolic composition and magnitude of copigmentation in young and shortly aged red wines made from the cultivars, Cabernet Sauvignon, Cencibel, and Syrah. Food Chem. 92, 269-283.

Hu, Y.D., 2009. Pressure treatment on sterilization effectiveness and quality of the enzyme inactivation of grapefruit juice. Thesis, Zhejiang Technology and Business University, China.

Huang, L., Sun, Y.M., Pan, K., Chen, B.W. \& Huang, W., 2007. High pressure treatment on quality of litchi juice. J. Agric. Eng. 2, 259-262.

Jorgensen, E.M., Marin, A.B. \& Kennedy, J.A., 2004. Analysis of the oxidative degradation of proanthocyanidins under basic conditions. J. Agric. Food Chem. 52, 2292-2296.
Kang, W.H., Li, H., Yang, X.F. \& Duan, X.R. 2006. Micro oxygen in the wine aging. Food Sci. Technol. Int., 32, 77-80

Kang, W.H., Li, H., Zhang, J.C., Yan, S.J., Yang, X.F. \& Zhang, Y., 2005 Impacts of micro-oxidation on polyphenols in dry red wine. Chin. Agric. Sci. Bul., 21 (12):103-104.

Karagiannis, S., Economou, A. \& Lanaridis, P., 2000. Phenolic and volatile composition of wines made from Vitis vinifera L. Muscat Lefko from the island of Samos. J. Agric. Food Chem. 48, 5369-5375.

Kinugasa, H., Takeo, T., Fukumoto, K., Shinno, T. \& Ishihara, M., 1993. Processing and preservation of tea extract by hydrostatic pressure. Biol. SCi. Food Sci., Hayashi, R. Tokyo, pp 237-243.

Kühnau, J., 1976. The flavonoids, a class of semi-essential food components: their role in human nutrition. World Rev. Nutr. Diet. 24, 117-191.

La Torre, G.L., Saitta, M., Vilasi, F., Pellicano, T. M., Dugo, G., 2006 Direct determination of phenolic compounds in Sicilian wines by liquid chromatography with PDA and MS detection. Anal. Nutrit. Clin. Meth. 94, 40-650

Lamikanra, O., 1997. Changes in organic acid composition during fermentation and aging of noble Muscadine wine. J. Agric. Food Chem. $45,935-937$.

Lee, J.H. \& Stephen, T.T., 2002. Ellagic acid and ellagitannins affect on sedimentation in Muscatine juice and wine. J. Agric. Food and Chem. 50, $3971-3976$

Lee, S.Y., Dougherty, R.H. \& Kang, D.H., 2002. Inhibitory effects of high pressure and heat on Alicyclobacillus acidoterrestris spores in apple juice. Appl. Environ. Microbiol. 68, 4158-4161.

Li, B.S., Zhang,W. \& Mei, C.H., 2010. Comparison of ultra-high pressure and heat sterilization on the quality of freshly squeezed pineapple juice. Agric. Eng. 1, 359-364

Li, H., Wang, J., Lv, Y., Xu, L.Q. \& Guo, H.F. 2007. The impact of microwave on the sensory indicators anthocyanin, chroma, hue, and the total acid concentration of dry red wine. Thesis, Hebei Agricultural University, China.

Li, L., 2010. The impact of high pressure treatment on sterilization and the browning mechanism of sauerkraut. Thesis, China Agricultural University, China.

Li, J.R., Fu, Y.H., Gu, Z.Y. 1999. The impacts of high pressure on ageing rice wine. Food Sci. Technol. Int. 25, 36-42.

Li, S.F., Duan, X.C., Liu, S.W., Yang, G.M., 2005, The impacts of high pressure treatment on the physical properties of fresh dry red wine. Winemaking Tech., 8:61-64.

Lin, Q. \& Chen, D.H.,2002. The application of microwave radiation in organic synthesis. Fuzhou Normal College 22 (2), 25-28.

Liu, X.J., Yin, Y.G., Fan, S.M. \& Zhu, C. 2006. Artificial technology of wine aging. Forset Spec. 6, 66-69.

Liu, X.J., Yin, Y.G., Zhu, C., Fan, S.M. \& Luo, G.C. 2007. High voltage pulsed electric field on the chromaticity of dry red wine. Food and Machinery 23, 51-52.

Liu, Y., 2010. The impacts of high pressure carbon dioxide, and high pressure treatment on the quality and flavor of freshly squeezed watermelon juice. Thesis, China Agricultural University, China.

Martin, J.D., Luis, B.M. \& Lopez, M.C. 2002. Effect of caffeic acid on the color of red wine. J. Agric. Food Chem. 50, 2062-2067.

Mateus, N., Carvalho, E., Carvalho, A.R.F., et al., 2003. Isolation and structural characterization of new acrylated anthocyanin-vinyl-flavanol pigments occurring in ageing red wines. J. Agric. Food Chem. 51, 277-282

Minussi, R.C., Rossi, M., Bologna, L., Cordi, L., Rotolio, D., Pastore, G.M. \& Durán, N., 2003. Phenolic compounds and total antioxidant potential of commercial wines. Food Chem. 82, 409-416. 
Monagas, M. \& Garmen, G.C., 2006. Evolution of the phenolic content of red wines from Vitis vinifera L during ageing in the bottle. Food Chem. 95, 405-412.

Pekić, B., Kovač, V., Alonsod, E., et al., 1998. Study of the extraction of proanthocyanidins from grape seeds. Food Chem. 61, 201-206.

Pérez Magariňo, S., Ortega-Heras, M., Gonzáles-San \& José, M.L., 2002. Multivariate classification of rose wines from different Spanish protected designations of origin. Anal. Chim. Acta, 458, 187-190.

Polydera, A.C., Stoforos, N.G., Taoukis, P.S., 2003. Comparative shelf life study and vitamin $\mathrm{C}$ loss kinetics in pasteurized and high pressure processed reconstituted orange juice. J. Food Eng. 60, 21-29.

Proestos, C., Bakogiannis, A., Psarianos, C., Koutinas, A.A., Kanellaki, M. \& Komaitis, M., 2005. High performance liquid chromatography analysis of phenolic substances in Greek wines. Food Control 16, 319-323.

Ramos, R., Andrade, P.B., Seabra, R.M., Pereira, C., Ferreira, M.A. \& Faia, M.A., 1999. A preliminary study of non-colored phenolic in wines of varietal white grapes (códega, gouveio and malvasia fina): effects of grape variety, grape maturation and technology of winemaking. Food Chem. 67, $39-44$

Recamales, A.F., Sayago, A., Gonzalez-Miret, M.L. \& Hernanz, D., 2006. The effect of time and storage conditions on the phenolic composition and colour of white wine. Food Res. Int. 39, 220-229.

Remy, S., Fulcrand, H., Labarbe, B, Cheynier, V. \& Moutounet, M., 2000. First confirmation in red wine of products resulting from direct anthocyanintannin reactions. J. Sci. Food Agric. 80, 745-751.

Revilla, I. \& González-SanJosé, M., 2003. Compositional changes during the storage of red wines treated with pectolytic enzymes: low molecularweight phenols and flavan-3-ol derivative levels. Food Chem. 80, 205-214.

Ribereau-Gayon, P., Pontallier, P. \& Glories, Y., 1983. Some interpretations of colour changes in young red wines during their conservation. J. Sci. Food and Agric. 3,: 506-516.

Rodrigo, D., Jolie, R., Van Loey, A. et a1., 2007. Thermal and high pressure stability of tomato lipoxygenase and hydro peroxide lyase. J. Food Eng. 79, 423-429.

Rodrigo, D., Jolie, R., Van, Loey, A. \& Hendrickx, M., 2007. Principal component analysis of the polyphenol content in young red wines. Food Chem. 78, 523-532.

Salas, E., Fulcrand, H. \& Meudec, E., 2003. Ions of anthocyanins and tannins in model solutions. J. Agric. Food Chem. 51, 7951-7961.

Sancho, F., Lambert, Y., Demazeau, G. et a1., 1999. Effect of ultra-high hydrostatic pressure on hydro soluble vitamins. J. Food Eng. 39, 247-253.

Schwarz, M., Picazo-Bacete, J.J., Winterhalter, P., Hermosín-Gutiérrez, I., 2005. Effect of copigments and grape cultivar on the color of red wines fermented after the addition of copigments. J. Agric. Food Chem. 53, 83728381 .

Shahidi, F. \& Wanasundara, P.K., 1992. Phenolic antioxidants. Crit. Rev. Food Sci. Nutr. 32, 67

Shimada, S., Andou, M. \& Naito, N., 1993. Effects of hydrostatic pressure on the ultra-structure and leakage of internal substances in the yeast Saccharomyces cerevisiae. Appl. Microbiol. Biotechnol. 40, 123-131.

Somers, T.C., Verette, E. \& Pocock, K.F., 1987. Hydroxycinnamate ester of Vitis vinifera: Changes during white vinification, and effects of exogenous enzymic hydrolysis. J. Agric. Food Chem. 40, 67-78.
Su, H.N., 2008. The impacts of pulsed electric fields and magnetic fields on anthocyanin and organic acid of wine. Thesis, China Agricultural University, China.

Suzuki, A., Watanabe, M., Iwamura, K., Ikeuchi, Y. \& Saito, M., 1990. Effect of high pressure treatment on the ultrastructure and myofibrillar protein of beef skeletal muscle. Agric. Biol. Chem. 54, 3085-3091.

Tierney, S. \& Martin, H., 2005. Kinetics of microwave-assisted polymerization of $\varepsilon$-caprolactone. Synth. Metal. 148-195.

Versari, A., Boulton, R.B. \& Parpinello, G.P., 2008. A comparison of analytical methods for measuring the color components of red wines. Food Chem. 106, 397-402.

Vidal, S., Cartalade, D., Souquet, J.M., Fulcrand, H. \& Cheynier, V., 2002. Changes in proanthocyanidins chain length in wine like model solutions. J. Agric. Food Chem. 50, 2261-2262.

Vidal, S., Courcous, P. \& Francis, L., 2004. Use of an experimental design approach for evaluation of key wine components on mouth-feel perception. Food Qual. Pref. 15, 209-217.

Wang, Y.X., Lou, X.Z., Chen, X.W. \& Wu F.H. 2008. Food high pressure technology mechanism, impact factor and auxiliary means. Food Sci. Technol. 9, 127-130.

Wen, P.F. \& Huang, W.D., 2005. Studies on flavanols in wine and grape berry and expression of genes involved in proanthocyanidins biosynthesis during berry development. Thesis, China Agricultural University, China.

Wen, P.F., Chen, J.Y., Li, J.M., Zhan, J.C., Wan, S., Kong, W.F. \& Huang, W.D., 2006. Effect of oak barrel on the flavan-3-ols and proanthocyanidins in red wine during aging. Food Sci. 27(4), 110-114.

Xia, G.L., Liu, C.S., Shi, M.L., Shao, L. \& Zhang, Q.B., 2008.The application of micro-oxidation technology during wine aging. Domestic and foreign grape and wine 3, 16-18

Yang, H.F, Zeng, X.A. \& Chen, Y., 2003.The impacts of high-strength electromagnetic field on artificial aging of fresh wine. Brewing 30(3), 40-42.

Zhang, J.S., Zhang, W.Y. \& Tan, H.X. 2007. Pressure treatment-volatile chemical composition of the peach juice. Fine Chem. 24, 265-268.

Zhang, Q.H., Chen, X.B., Zhan, J.C., Tian, R.R., Wang, X.Q. \& Huang, W.D., 2008. Field fresh dry red wine polyphenols affect the food industry. Food Sci Technol. 29, 108-111.

Zhang, W.J., Zhang, Y., Liao, X.J., Wu, J.H., Chen, F., Sun, Z.J., Hu, X.S., 2008. The study of the impacts of high pressure on the quality of fruit and vegetable juices. Food Sci. Technol. 9, 113-117.

Zhao, G.Y., Zhang, P.Q. \& Bai, Y.H., 2007. The impact of hot and high pressure treatment on the quality of apple juice. Thesis, Hebei University of Technology, China.

Zhao, Y.,2008.The study on dry red wine aging. Thesis, Hebei Agricultural University, China.

Zhou, X.F., Gao, C. \& Wang, X.F., 2010. Oak chips and ultrasonic reminder Chen dry red wine brewing in China 8, 83-87.

Zimman, A., Joslin, W.S., Lyon M.L. \& Meier, J. 2002. Maceration variables affecting phenolic composition in commercial-scale Cabernet Sauvignon winemaking trials. Am. Soc. Enol. Vitic. 53, 93-98. 